\title{
Non-Hodgkin's Lymphoma of Nasal Cavity and Paranasal Sinuses: A Case Report
}

\author{
S. Tadsaoui , M. Ouha, A. Chehboun, M. ouha, B. Boutakioute, M. Ouali Idrissi, N. Cherif Idrissi El Ganouni
}

Radiology Department, Arrazi Hospital, Mohammed VI university hospital, Marrakech

DOI: $10.36347 /$ sasjm.2020.v06i12.007

| Received: 16.10 .2020 | Accepted: 31.10.2020 | Published: 30.12 .2020

*Corresponding author: Samira Tadsaoui

Abstract

Case Report

Non-hodgkin lymphoma (NHL) is rare tumors of the jaws. Their locations in the air spaces of the face coming in second row. We related the case of a primitive NHL located in two maxillary sinuses with an extension to the nasal and orbital fossa in a patient of 41 year, which illustrates the diagnostic difficulties encountered face a little suggestive symptoms .The diagnosis was confirmed by histological examination. In this observation, we will review the literature in order to review the clinical, radiological, histological, and therapeutic and outcome of this rare disease.

Keywords: Lymphoma, non-Hodgkin, maxillary sinus.

Copyright $\odot 2020$ The Author(s): This is an open-access article distributed under the terms of the Creative Commons Attribution 4.0 International License (CC BY-NC 4.0) which permits unrestricted use, distribution, and reproduction in any medium for non-commercial use provided the original author and source are credited.

\section{INTRODUCTION}

Non-Hodgkin's malignant lymphomas (NHML) represent the set of monoclonal malignant proliferations beginning in lymphoid tissue affecting B or $\mathrm{T}$ cells and which do not meet the definition of Hodgkin's disease. The mode of revelation of NHML is lymph node in $2 / 3$ of cases and extra-ganglionic in $1 / 3$ of cases. The localization in the nasal cavity and paranasal sinuses comes after that of the Waldeyer's ring (20). Its frequency is estimated between 7 and $22 \%$ of ORL lymphomas. The diagnosis of these locations, which is difficult to assess on clinical examination, is more difficult and requires CT imaging (21).

Histologically, the diffuse large B-cell forms are predominant in paranasal locations and, in particular, in the maxillary sinus (14). Centrofacial involvement is of $\mathrm{T}$ origin and has a poorer prognosis (1).

The case of a primary NHL localized to the maxillary sinus discovered after a facial swelling, proptosis and unilateral blindness has been reported, it illustrates the diagnostic difficulties encountered when faced with a symptom that is not very suggestive.

\section{CASE REPORT}

This is a 41-year-old man, with no particular medical and surgical history, who presents with an inflammatory right cheek swelling that has been evolving for two years, complicated by exophthalmos and blindness of the left eye that have developed since. 2 months.

Clinical examination showed a bilateral inflammatory jugular swelling more marked on the right side associated with exophthalmos of the left eye.

The buccal cavity examination revealed an alveolar arch, going from tooth 15 to the tuberosity of the maxilla, and which overhangs the adjacent palate without filling the vestibule, this arch was cracked along the alveolar arch (figure 1). Palpation revealed a firm and very sensitive consistency with bilateral cervical lymphadenopathy.

The CT scan revealed a voluminous aggressive tissular mass centered on the two maxillary sinuses, causing osteolysis of their bony walls and of the right bony palate with infiltration of the opposite soft tissues, in particular the pterygoid muscles with extension to the nasal fossa. Left eye thus responsible for grade III proptosis; associated with endocranial extension (figure 2).

The craniofacial and orbital MRI showed a tumor of the two maxillary sinuses and of the left nasal fossa with iso signal on T1 and hyper signal on T2 with a heterogeneous enhancement after contrast media injection, with extension to the deep spaces of the face, to the maxillary bone, to the palate, the nasopharynx, left orbit and base of the skull (Figure 3). 
These clinical and radiological elements suggested a malignant tumor. With this in mind, a biopsy was carried out revealing: a malignant tumor proliferation, the cells are large or medium in size arranged in diffuse layers, associated with large foci of ischemic-looking necrosis.

A complementary immunohistochemical study was carried out, it objectified:

- Anti Bcl-6: positive in 10\% of tumor cells.

- Anti CD20: positive

- Anti-Ki-67 Antigen: positive in 20\% of tumor cells.

- $\quad$ Lack of expression of anti CD3 and anti CD10.

All of these elements are characteristic of nonHodgkin's large cell malignant lymphoma of the B phenotype.

An extension assessement including chest $\mathrm{x}$ ray, abdominal ultrasound, and thoraco-abdominal CT was performed and did not identify other secondary locations.
We therefore concluded to a primary nonHodgkin's type B malignant lymphoma localized in the maxillary sinuses and classified as stage IV according to the Ann Arbor classification.

The patient was referred to the oncology department for further treatment.

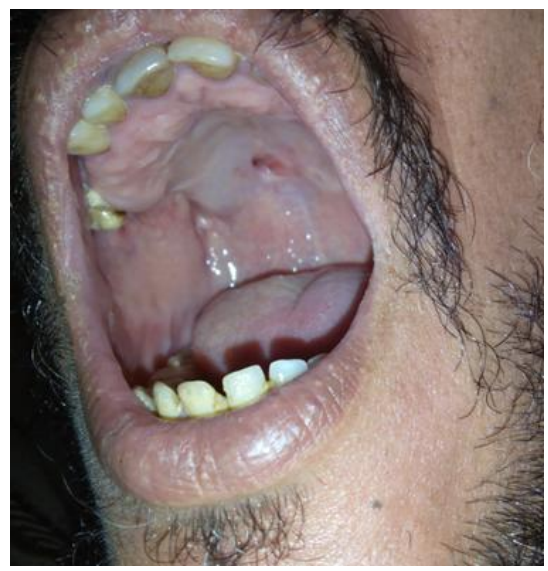

Fig-1: buccal examination: arching of the palatal arch going from tooth 15 to the tuberosity of the maxilla, with cracking of the bony palate

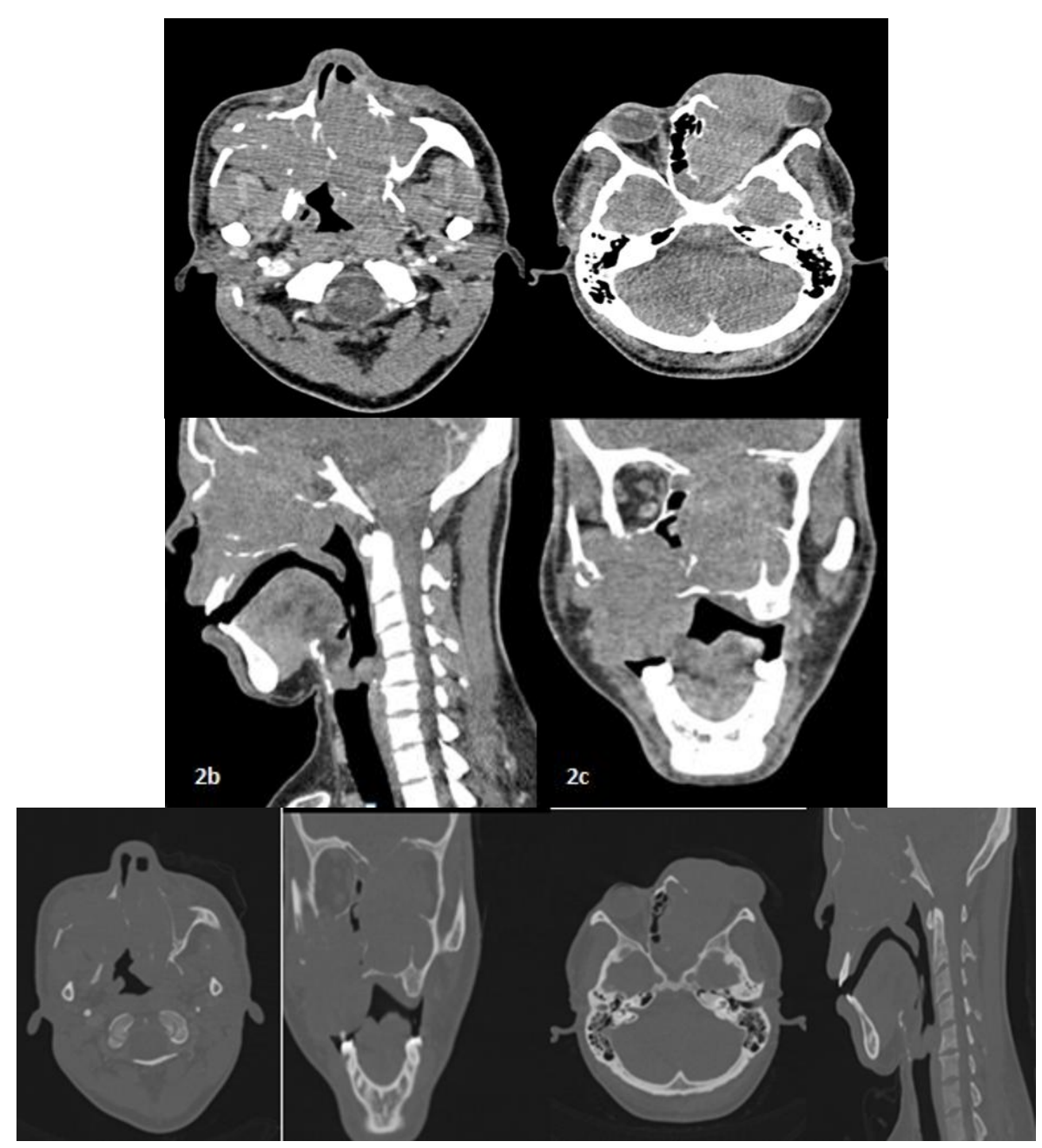

Figure-2 and 3: Facial CT: axial slices (a), coronal and sagittal reconstructions (b) and (c) in mediatisnal and bone window: showing a voluminous aggressive masses centered on the two maxillary sinuses and causing an osteolysis of their bone walls, from the bony palate and the sphenoid body with endocranial extension, to the nasal cavity and to the left eye 


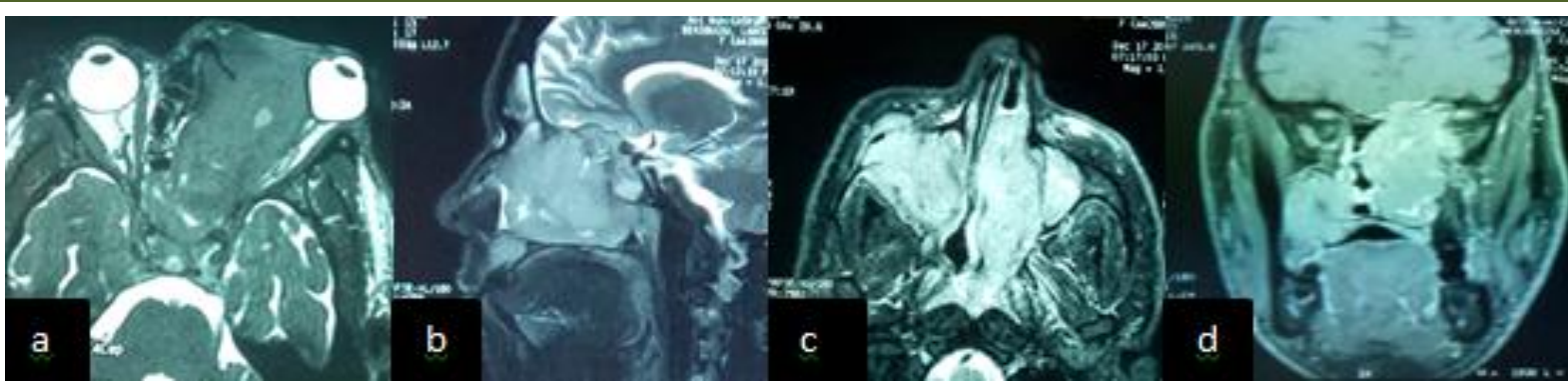

Fig-4: Craniofacial and orbital MRI, axial and sagittal T2 sequence (a, b) and axial and coronal T1 sequence with Gadolinium injection (c, d): demonstrating a tumor process of the two maxillary sinuses and the left nasal fossa that is hypersignal on $\mathrm{T} 2$ with heterogeneous enhancement and extension to the deep spaces of the face, the jawbone, the bony palate, the nasopharynx, the left orbit and at the base of the skull

\section{DISCUSSION}

Non-Hodgkin's malignant lymphomas constitute a heterogeneous set of lymphoid proliferations affecting $\mathrm{B}$ or $\mathrm{T}$ cells. The mode of revelation is lymph node in $2 / 3$ of cases and extra lymph node in $1 / 3$ of cases.

In the cervicofacial extremity, Waldeyer's lymph ring is the most common site of NHL, followed by the major salivary glands, in this case the parotid gland and the submandibular gland [1]. In contrast, NHL of the nasal cavity and paranasal sinuses remains exceptional and represents only $0.17 \%$ of all lymphomas [2] and only $3 \%$ of cervicocephalic neoplasias [3]. The most frequent histological type is type B, while type T remains exceptional [3].

These lymphomas most commonly occur in the sixth decade of life, with a slight male predominance [4]. The clinical manifestations are not specific [5]. If the general signs are rare, the local signs are mainly represented by an often old nasal obstruction, more rarely a rhinorrhea or recurrent epistaxis [5]. Finally, the ophthalmological signs can be rarely revealing such as an exophthalmos (1.5 to 5). \%) $[6,7]$, decreased visual acuity or limited eye movements.

The differential diagnosis arises mainly with other tumors of the jaw, in particular with squamous cell carcinoma [8]. The differential diagnosis also includes mucoceles, infectious aetiologies (acute and chronic sinusitis), antrochoanal inflammatory polyp and tumors (benign, malignant and metastatic) [2].

In conventional imaging, the images observed reflect bone invasion and/or tumor extension. The bony localization of a malignant lymphoid proliferation takes on the appearance of a diffuse radiolucency with disappearance of the lamina dura in the dentate sectors and from the bottom sinus border to the maxilla [9]. However, the radiological appearance of a malignant epithelial tumor is that of frank and massive osteolysis [10].
Computed tomography examination is essential for assessing bone invasion and for estimating the size of the lesion for its TNM classification [10]. Lymphomatous lesions are usually parenchymal in appearance, isodense, with invasion of neighboring cavities. The bone walls are most often eroded decalcified, lysed, with a honeycomb-like areolar appearance. In fact, the late onset of bone involvement compared to the onset of the disease, the mildness of the bone involvement contrasting with extensive tumor formation may be suggestive of lymphomatous etiology $[4,5]$.

Magnetic resonance imaging (MRI) has an interest in the assessment of extension to adjacent structures and also allows differentiating the tumor process from an inflammatory lesion [11]. lymphoma appears iso intense before injection, moderately enhanced by the contrast product and differentiating from retention fluids on $\mathrm{T} 2$ sequences by its relative iso signal [12] Intraorbital extension results in a mass, surrounding and/or infiltrating the retro-orbital nerve, fatty and muscular structures, which can lead to exophthalmos.

The definitive diagnosis can only be established by the histological definition of tumor proliferation and the characterization of its phenotype by immunohistochemical study [13]. These immunohistochemical criteria are essential for therapeutic management because, along with the stage of the disease, they are the two main prognostic factors $[14,15]$.

The most widely used classification system for staging NHL is the Ann Arbor system, which considers the number of tumor sites (lymph node and extranodal) and their location, as well as the presence or absence of B symptoms [16-17].

The treatment of these lymphomas is based on polyvalent chemotherapy isolated or associated with external radiotherapy (30 to 50 Grays) in the most advanced cases (T3, T4) [18]. The isolated clinical forms (stage IA E) are usually of good prognosis with a survival ranging from $70 \%$ to $100 \%$ at 5 years $[1,14]$. 
Overall 5-year survival is $30-60 \%$ in stages I-II and drops to $30 \%$ for more advanced stages [19].

\section{CONCLUSION}

Nasosinus lymphomas represent a rare entity, characterized by an initial symptomatology often rough, delaying the diagnosis. Imaging is nonspecific, and the diagnosis remains histological. Chemotherapy adjuvant to radiotherapy gives good results. The prognosis depends on the histologic type, the Ann Harbor stage at diagnosis and the therapeutic possibilities for each patient.

\section{REFERENCES}

1. Epsteinjd, Lend, Gorskym. Characteristics of oral and paraoral malignant lymphoma: a populationbased review of 361 cases. Oral Surg Oral Med Oral Pathol Oral RadiolEndod. 2001; 92:519-25.

2. Védrine PO, Baudet B, Meghachi AS. Lymphome malin non hodgkinien du sinus sphénoïdal. Fr ORL 2005;88: 120-3.

3. Métellus P, Fuentes S, Figarella-Branger D, Dufour H, Grisoli F. Lymphome primitif du sinus sphénoïdal : à propos d'un cas et revue de la littérature. Neurochirurgie. 2002; 48(6):522-6.

4. El messaoudi A, Lazrak A, Essakali L, Jazouli N. Difficultés diagnostiques posées par le lymphome malin non hodgkinien à localisation sinusienne: à propos d'un cas. Les Cahiers d'oto-rhinolaryngologie, de chirurgie cervico-faciale et d'audiophonologie. 1992;27(2):71-3.

5. Bruneton JN, Serres JJ, Normand F. Lymphomes des cavités aériques de la face. J Radiol. 1987;68(12):785-8.

6. Pignat JC, HaguenauerJP,Ghouliha C. .Lymphome malins non Hodgkineinscervicofaciaux, classification, pronostic et traitement à partir de 65 ans .Ann otolaryng (Paris). $1989 ; 106, \mathrm{n}^{\circ} 1$ :37-39

7. Conely SF, Staszak C, Clamon G, Maves M. NonHodgkin's lymphoma of the head and neak: the university of iowa experience. Larygoscope, 1987; 97:291-300.

8. Abbondanzosl, Weotingbm. Non-Hodgkin's lymphoma of the sinusonasal tract. À clinicopathologic and immunophenoypic study of 120 cases. Cancer. 1995; 75:1281-90.

9. Epstenjb, Waisglassm, Bhimjis, Len, Stevensonmoorep. À comparison of computed tomography and panoramic radiography in assessing malignancy of the maxillary antrum.Eur $\mathbf{J}$ Cancer B Oral Oncol. 1996; 32B: 191-201.

10. Matsumotos, Shibuyah, Tateras, Yamazakie, Suzukis. Comparison of CT findings in nonHodgkin lymphoma and squamous cell carcinoma of the maxillary sinus.ActaRadiol. 1992; 33: 523-7.

11. Derbel, Ben Zina, Sellami, Ben Ayed, Chaabouni, Daoud , Frikha ,Abdelmoula.Exophtalmie et cécitérévélant un lymphoma malin non hodgkinienethmoido-maxillaire à cellules T.J.Fr Ophtalmo. 1999:22,5:566-570.

12. Duverneul NM, ChirasJ.Imageriemaxillafacilae. Imagerie médicale dirigée par Henri Nah 13. Yasumotom, Tuaras, Shibuyah, Hondam. Primary malignant lymphoma of the maxillary sinus: CT and MRI. Neuroradiology. 2000; 42: 285-9.

13. Nakamurak, Ueharas, Omagarij, Kunitaken, Jinguk, Masudak. Primary Non- Hodgkin's Lymphoma of the Maxillary Sinus.Am J ClinOncol. 1997; 20: 272-5.

14. Vidalrw, Devaneyk, Ferlitoa, Rinaldoa, Carbonea. Sinonasal malignant lymphomas: a distinct clinicopathological category. Ann OtolRhinolLaryngol. 1999; 108: 411-9.um.

15. Lu P. Staging and classification of lymphoma. SeminNucl Med. 2005;35(3): 160-4.

16. Kemp S, Gallagher G, Kabani S, Noonan V, O'Hara C. Oral non-Hodgkin's lymphoma: review of the literature and World Health Organization classification with reference to 40 cases. Oral Surg Oral Med Oral Pathol Oral RadiolEndod. 2008;105(2):194-201. Epub 2007 Jun 29.

17. Proulxgm, Caudra- Garciai, Ferryj, Harrisn, Grecowr, Kayau, Chana, Wangcc. Lymphoma of the nasal cavity and paranasal sinuses: treatment and outcome of early-stage disease. Am J ClinOncol. 2003; 26: 6-11.

18. B. Hemmaoui, K. Nadour, N. Errami, N. Touiheme, A. Aljalil, M. Elmarjany, K. Doghmi, F. Benariba. Lymphome primitif nasosinusien:à propos d'un cas.La Lettre du Cancérologue Vol. XXI - n 3 - mars 2012

19. HaicounC, Reyes F. Lymphomes malin non Hodgkiniens de la tête et du cou, l'hématologie de Bernard Dreyfus .Flmamarion. 1992 :913-914

20. Guerrier Y, Smadja JG. Les lymphomes malin non Hodgkiniens Encycl.Méd.chir.Paris, PRL, 20950 C10, 4-1983. 